\title{
Pseudocapacitive Behavioral Testing of Iron Vanadate Nanoparticles Synthesized by Simple Co- Precipitation Method
}

\author{
S. Ezhil Arasi, P. Devendran, R. Ranjithkumar, M. Krishnakumar, A. Arivarasan
}

\begin{abstract}
Iron vanadate nanoparticles were prepared by simple co-precipitation method. The crystal structure and elemental composition of prepared material were confirmed using $X$-ray Diffraction analysis and Elemental Dispersive $X$ - ray spectroscopic analysis respectively. Surface morphology of the sample was analyzed by Scanning Electron Microscopic techniques. Optical absorption and molecular vibrations were studied by UV-Vis. absorption spectroscopy and Fourier Transform Infrared spectroscopic techniques. Electrochemical behaviors such as redox property, charge-discharge mechanism and impedance analysis were examined with cyclic voltammetry, Galvanostatic charge-discharge and electrochemical impedance spectroscopic studies.
\end{abstract}

Keywords: Iron vanadate nanoparticles, cyclic voltammetry, charge-discharge, and supercapacitor.

\section{INTRODUCTION}

$T_{\text {he intrinsic properties of the nanomaterials especially }}$ the inorganic materials with controlled size, compositions and morphology attracts much interest. The co-precipitation method performed in room temperature with surfactants and controlled $\mathrm{pH}$ is considered to be the easy and effective method to prepare inorganic nanomaterials with desired morphology, size and shape. In past few decades, transition metal vanadate nanoparticles have been attracting due to their applications in energy storage, photo catalysis and energy conversion devices [1-4].

In transition metals oxides, vanadium and iron has numerous applications in various fields as it contains different valance states, maximized electrochemical activity, etc $[5,6]$. They have been used as an electrode material in recent

Revised Manuscript Received on December 15, 2019.

* Correspondence Author

S. Ezhil Arasi, Department of Physics, Kalasalingam Academy of Research and Higher Education, Krishnankoil, Tamil Nadu 626126, India. Email: arasi1105@gmail.com

P. Devendran, Department of Physics, Kalasalingam Academy of Research and Higher Education, Krishnankoil, Tamil Nadu 626126, India. Email: pdevavenmani@gmail.com

R. Ranjithkumar, Department of Physics, Kalasalingam Academy of Research and Higher Education, Krishnankoil, Tamil Nadu 626126, India. Email: ranjithphy14012@gmail.com

M. Krishnakumar, Department of Physics, Kalasalingam Academy of Research and Higher Education, Krishnankoil, Tamil Nadu 626126, India. Email: m.krishnakumar@klu.ac.in

A. Arivarasan*, Department of Physics, Kalasalingam Academy of Research and Higher Education, Krishnankoil, Tamil Nadu 626126, India. Email: arivarasan.nanotech@gmail.com

decades. In connection with this, iron vanadate has various merits including its availability in nature, low toxicity, chemical stableness and user friendly in fabrication process. A wide variety of iron vanadate had been synthesized and investigated as they possess various application [7-15].

The electrochemical devices such as batteries, supercapacitors, and fuel cells have been used in day to day life. Among these, the supercapacitors are the current interests. In supercapacitors, there are three divisions such as pseudocapacitors, electric double layer capacitors and hybrid capacitors. The transition metal oxide electrode is used in pseudocapacitors; carbon-based electrodes are employed in electric double layer capacitors and finally the hybrid capacitors which uses both the pseudocapacitor and electric double layer capacitors [16-18].

In this work, the transition binary metal oxide i.e, iron vanadate nanoparticles are synthesized through coprecipitation method. The prepared iron vanadate nanoparticles are analyzed to determine the crystalline structure, functional, optical and morphological properties. Electrochemical behavior is investigated to examine the pseudocapacitance nature of the prepared iron vanadate nanoparticles. The main objective of this research work is to examine the electrochemical property of prepared iron vanadate nanoparticles in order to utilize the prepared iron vanadate nanoparticles as an electrode material for energy storage devices.

\section{EXPERIMENTAL SECTION}

\section{A. Chemicals}

Analytical grade Iron (III) chloride hexa hydrate $\left(\mathrm{Fe}(\mathrm{Cl})_{2} \cdot 6 \mathrm{H}_{2} \mathrm{O}\right)$, ammonium metavanadate $\left(\mathrm{NH}_{3} \mathrm{VO}_{4}\right)$, was used as the precursor material, polyvinylpyrolidine (PVP), sodium hydroxide $(\mathrm{NaOH})$ and ethanol were purchased from Sisco Research Laboratories Pvt. Ltd., Mumbai, India. All the chemicals with AR grade were used as purchased without further purifications. The entire reaction and electrolyte solutions were freshly prepared with deionized (DI) water. For electrochemical studies, potassium hydroxide $(\mathrm{KOH})$, Polyvinylidene fluoride (PVDF) and N-Methyl-2pyrrolidone (NMP) were purchased from sigma Aldrich. 


\section{Pseudocapacitive Behavioral Testing of Iron Vanadate Nanoparticles Synthesized by Simple Co- Precipitation Method}

\section{B. Iron vanadate nanoparticles synthesis and modified electrode fabrication}

Facile iron vanadate nanoparticles were prepared using Iron (III) chloride hexa hydrate, and ammonium metavanadate as precursor material. Stoichiometric amount of $0.1 \mathrm{M}$ of $\mathrm{Fe}(\mathrm{Cl})_{2} \cdot 6 \mathrm{H}_{2} \mathrm{O}$ and $0.1 \mathrm{M} \mathrm{NH}_{3} \mathrm{VO}_{4}$ was dissolved in $100 \mathrm{ml}$ of $\mathrm{DI}$ water. $0.1 \mathrm{M}$ of $\mathrm{NaOH}$ was added as the precipitating agent and to maintain the $\mathrm{pH}$ of reaction mixture at $7.0 .1 \mathrm{~g}$ of PVP was used as a surfactant. The reaction mixture was kept under constant stirring for $30 \mathrm{~min}$. and washed with DI water and ethanol. The final product was collected using centrifugation at $3000 \mathrm{rpm}$. The washed nanoparticles were dried in oven at $80{ }^{\circ} \mathrm{C}$ for $12 \mathrm{~h}$ and calcined at $650{ }^{\circ} \mathrm{C}$ for $3 \mathrm{~h}$. The doctor blade technique was employed to fabricate the modified electrode.

\section{Characterization techniques}

The crystalline structure of the prepared iron vanadate nanoparticles was studied by Bruker X-ray diffractometer (D8 advance ECO) with $\mathrm{Cu}-\mathrm{K}_{\alpha}$ radiation (1-1.5406 ̊). Scanning Electron Microscope (SEM) provided with Energy Dispersive X-ray Spectroscopy (EDS) and mapping was used to observe the surface morphology, and elemental distribution of iron vanadate nanoparticles using ZEISS-EVO 18 Research, Japan. Fourier transform infrared spectrometer (FTIR) was employed using a Shimadzu (IR Tracer-100) spectrophotometer within the range of $4000-400 \mathrm{~cm}^{-1}$ using $\mathrm{KBr}$ pellet system for functional group analysis. Electrochemical investigation was done using electrochemical workstation systemized with three electrode system (CH instrument $6008 \mathrm{E})$.

\section{RESULTS AND DISCUSSION}

\section{A. PXRD}

The Fig.1 depicts the powder X-ray diffraction (PXRD) pattern of prepared iron vanadate nanoparticles. The recorded PXRD patterns was matched with JCPDS card number 71-1592 and indexed with hkl planes [11,9-20]. The structure obtained was found to be primitive with cell parameters $a=6.719 b=8.060 \mathrm{c}=9.254$ and $\alpha=96.6, \beta=106.57, \gamma=101.60$. The sharp and broad peaks define the crystallization of nanoparticles with nanoscale size. This result was also coincided with the EDS spectrum as there were no additional phase peaks.

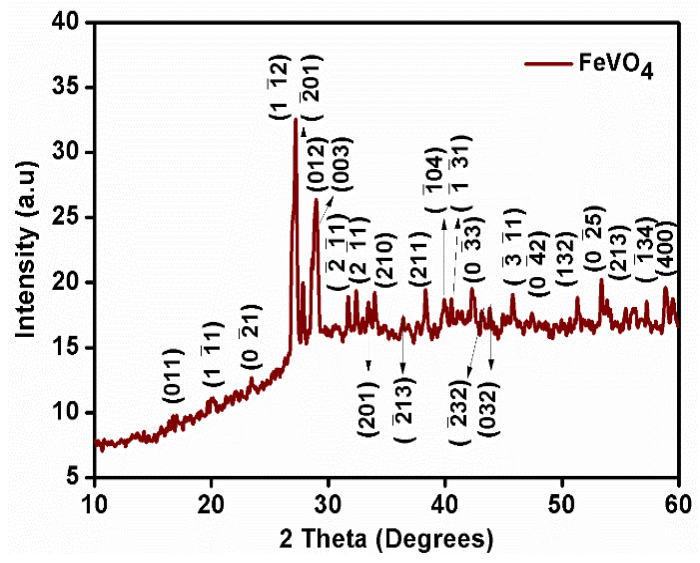

Fig. 1. Powder XRD pattern of prepared iron vanadate nanoparticles

\section{B. FTIR}

The Fig. 2 shows the FTIR spectrum of prepared iron vanadate nanoparticles. The peaks reveal that the prepared iron vanadate nanoparticles have been transmitted by vibration of atoms and molecules. The peak at $547 \mathrm{~cm}-1$ was due to the Fe-O vibrations. The V-O-Fe bonds stretching vibrations were absorbed in 819 and $918 \mathrm{~cm}-1$. The appearance of peak at $1045 \mathrm{~cm}-1$ was due to the V-O terminal stretching vibrations. Interactions between $\mathrm{Fe}, \mathrm{V}$ and $\mathrm{O}$ were observed through these peaks [21].

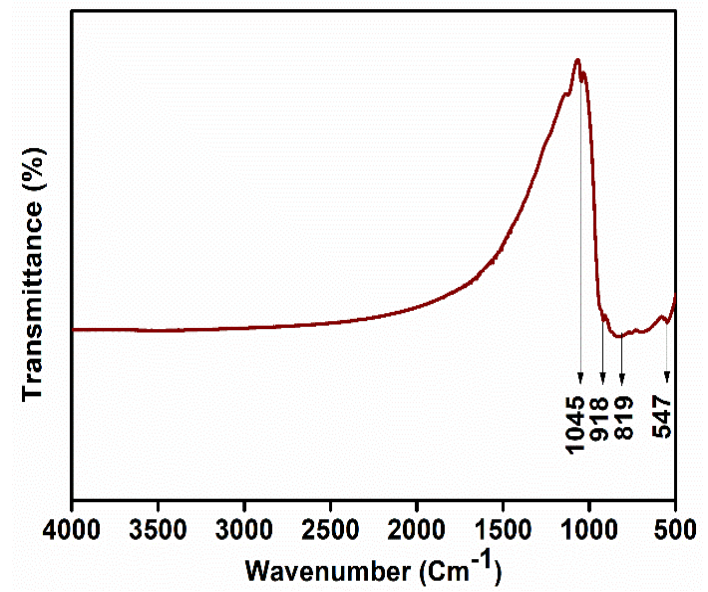

Fig. 2. FTIR spectrum of prepared iron vanadate nanoparticles

\section{UV-Vis. absorption spectroscopy}

The optical properties of prepared iron vanadate were studies with UV-Vis. absorption spectroscopy. Fig. 3 shows the presence of two absorption band edges of iron, vanadate nanoparticles. The absorption band edge at $318 \mathrm{~nm}$ was due to the iron and $369 \mathrm{~nm}$ was due to the vanadium compound present in synthesized iron vanadate nanoparticles. This clearly indicates that the prepared iron vanadate nanoparticles have the absorption behavior in UV region [22].

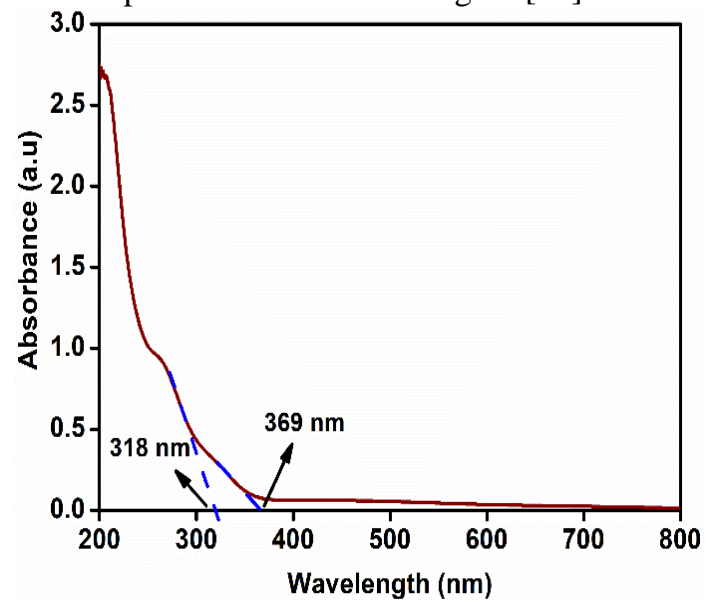

Fig. 3. UV-Vis. absorption spectrum of prepared iron vanadate nanoparticles

\section{SEM with EDS and Mapping}

The surface morphology of the prepared iron vanadate nanoparticles was studied by SEM analysis and the recorded images were shown in Fig. 4. 
The prepared iron vanadate has morphology of 2D layers. Higher magnification image, confirms that the 2D layers were combined together to form bigger sized particle of about 200 $\mathrm{nm}$ in size.
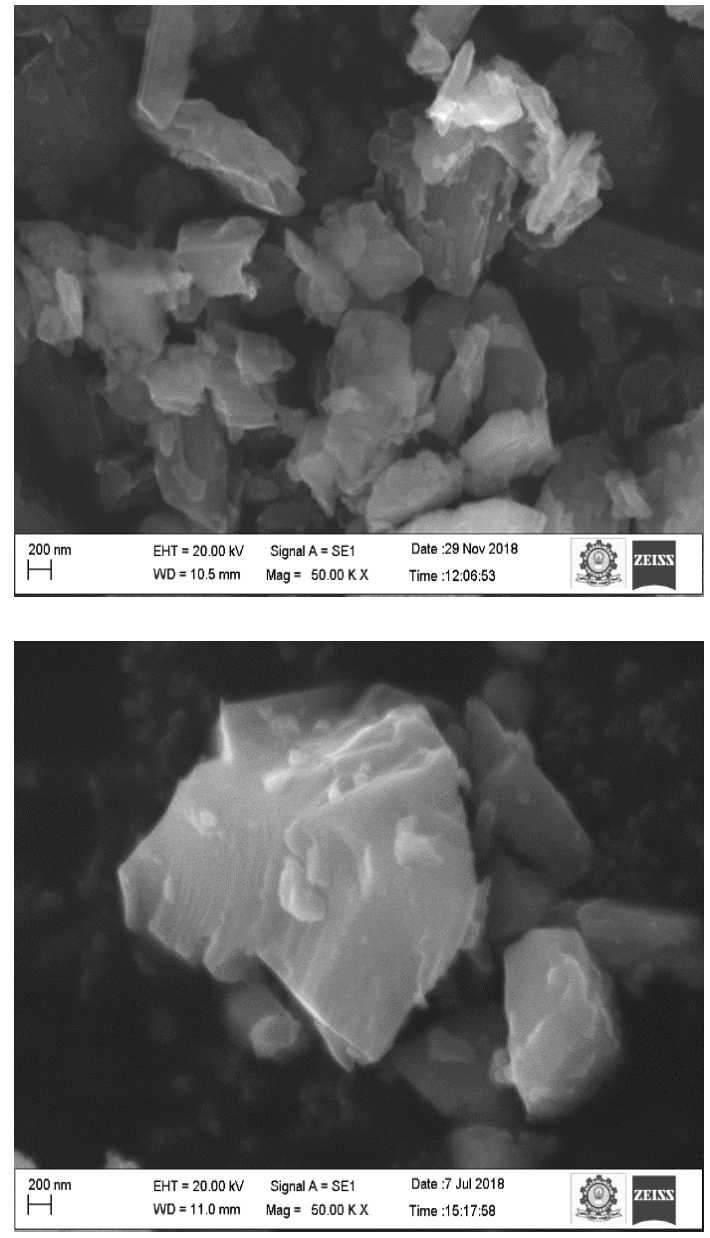

Fig. 4. SEM images of prepared iron vanadate nanoparticles
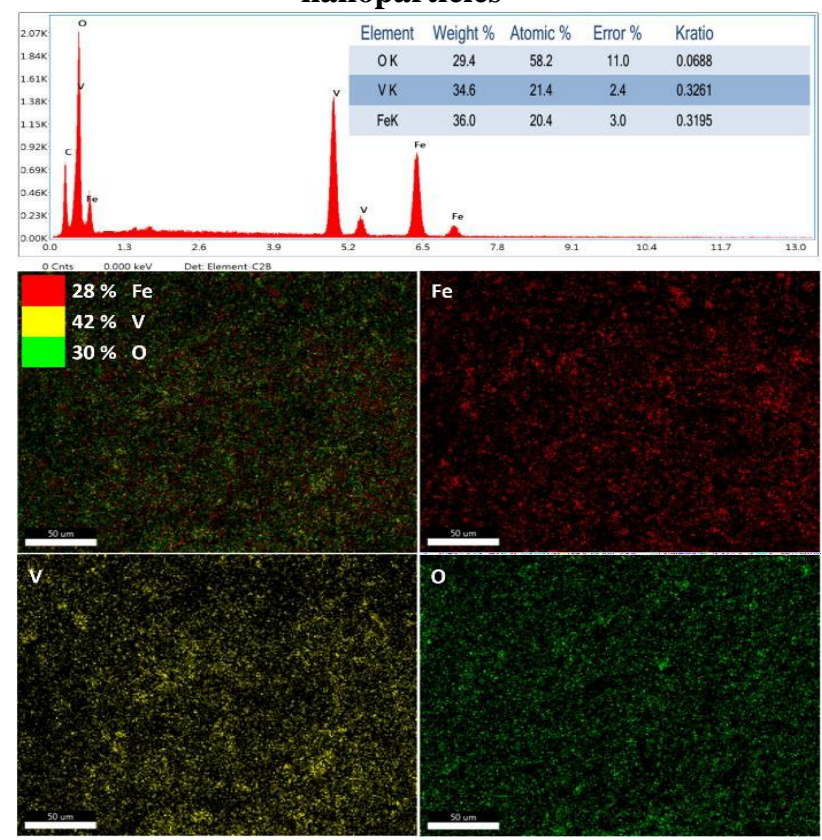

Fig. 5. EDS spectrum and mapping of prepared iron vanadate nanoparticles
EDS spectrum analysis helped in analyzing the composition of chemical elements and the purity of prepared iron vanadate nanoparticles. The EDS spectrum confirmed the high purity of synthesized compound by the presence of only $\mathrm{Fe}, \mathrm{V}$ and $\mathrm{O}$ peaks [15]. The weight percentage of $\mathrm{Fe}$ (36\%), V (34.6\%) and O (29.4\%) in EDS spectrum clearly confirmed the equimolar ratio $(0.1 \mathrm{M})$ of starting materials used in the synthesis process. The mapping image clearly depicts the homogeneous distribution of nanoparticles all over the surface. The weight percentage was found to be similar to that of EDS spectrum which coincide with XRD and mapping results which confirms the purity of the prepared iron vanadate nanoparticles.

\section{E. Electrochemical test}

The electrochemical behavior of prepared iron vanadate nanoparticles was analyzed with the help of cyclic voltammetry, galvanostatic charge discharge, and electrochemical impedance spectroscopy.

The CV curve of prepared iron vanadate nanoparticles were given in Fig. 6. The $\mathrm{CV}$ curves were recorded under different scan rate ranges from $10 \mathrm{mV} / \mathrm{s}$ to $100 \mathrm{mV} / \mathrm{s}$. The potential window was fixed between 0 and $0.5 \mathrm{~V}$. The redox peaks on anodic and cathodic region implies the pseudocapacitive behavior of the prepared iron vanadate nanoparticles. The curves were found to be similar for all the scan rates which reveals the stability of prepared nanoparticles $[23,24]$.

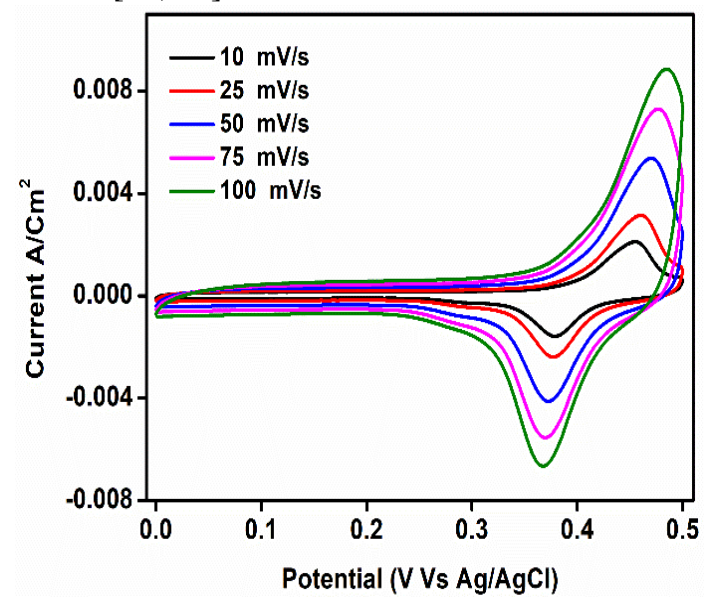

Fig. 6. CV curves of prepared iron vanadate nanoparticles

The charge storage and discharge ability of prepared iron vanadate nanoparticles were examined thorough galvanostatic charge-discharge process. Fig. 7 depicts the charge-discharge curves of prepared iron vanadate nanoparticles. The fixed potential was 0 to $0.5 \mathrm{~V}$. The applied current was 4 and $5 \mathrm{~mA} / \mathrm{cm} 2$. The discharge and charge capacity were almost same and found to have higher for lower current due to slow ion transfer [24].

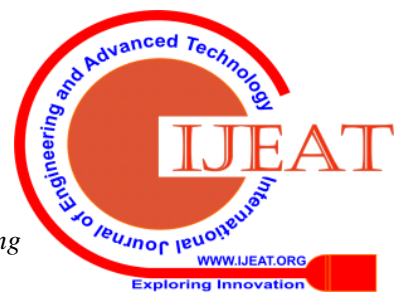




\section{Pseudocapacitive Behavioral Testing of Iron Vanadate Nanoparticles Synthesized by Simple Co- Precipitation Method}

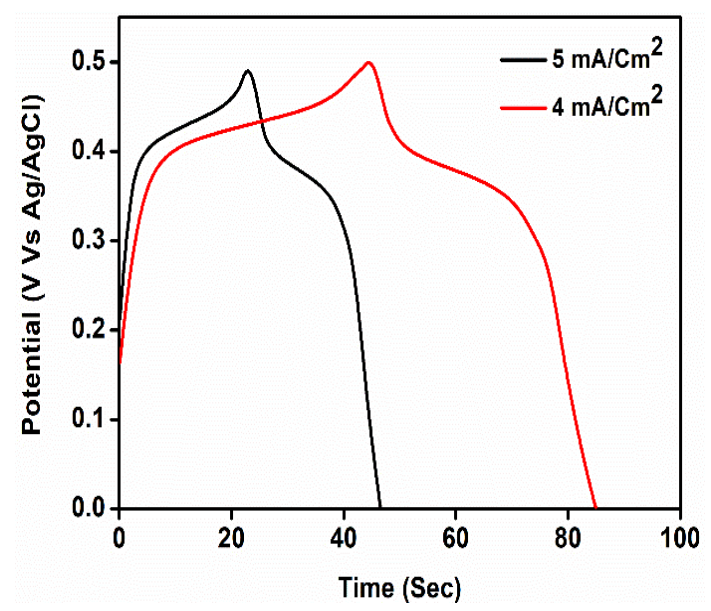

Fig. 7. GCD pattern of prepared iron vanadate nanoparticles

The EIS studies was done to measure impedance of prepared iron vanadate nanoparticles. Fig. 8. depicts the impedance curve of synthesized nanoparticles. The inset show the clear formation of semicircle around 1.5 to $1.6 \Omega$. In the mid-frequency region, the shorter semicircle was appeared which was then turned to spike when the frequency was lowered. This might be due to the charge transformation between electrode and electrolyte ions. The higher and lower frequency region contains the semicircle with spike which indicates the pseudocapacitive behaviour of the prepared iron vanadate nanoparticles. This is found to be in correspondence with other electrochemical results [25].

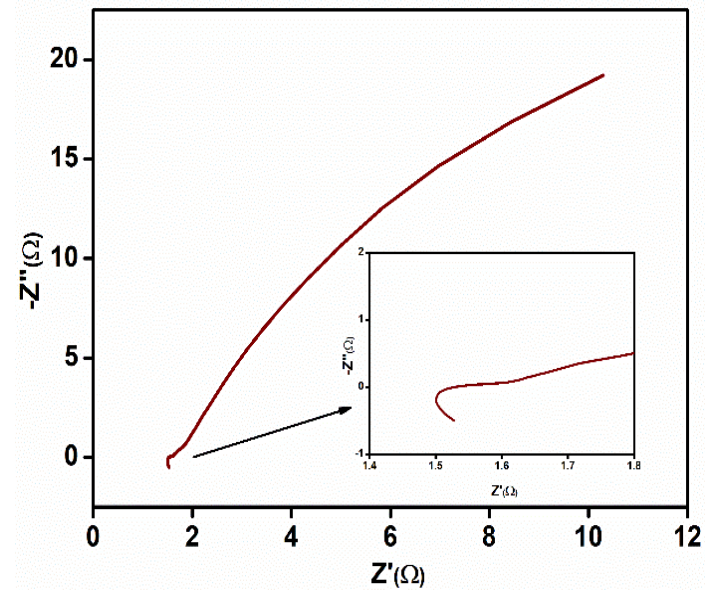

Fig. 8. EIS curve of prepared iron vanadate nanoparticles

\section{CONCLUSION}

In summary, the iron vanadate NPs was synthesized by simple co-precipitation technique. The prepared iron vanadate has primitive crystal structure and internal stretching vibrations between $\mathrm{Fe}, \mathrm{V}$ and $\mathrm{O}$ elements within the compound. The absence of other additional elemental peaks implies the purity of prepared NPs. The 2D layered morphology was observed through SEM images which might be due to the agglomeration of 2D layers to form bigger nanoparticles of size about $\sim 200 \mathrm{~nm}$. The absorption band edge at $318 \mathrm{~nm}$ and $369 \mathrm{~nm}$ were achieved by the absorption of iron and vanadium compounds which proved the presence of good optical property in the prepared iron vanadate nanoparticles. The redox curves, charge-discharge curve and impedance graph of prepared nanoparticles all together confirmed that the prepared iron vanadate nanoparticles possess pseudocapacitve behaviour.

\section{ACKNOWLEDGMENT}

Authors would like to acknowledge IRC, Kalasalingam Academy of Research and Education (KARE) for providing research facilities and owe thankful for funding under the University Research Fellowship (URF) scheme.

\section{REFERENCES}

1. M. C. Liu et al., "Synthesis and characterization of M3V2O8 (M=Ni or Co) based nanostructures: A new family of high performance pseudocapacitive materials," J. Mater. Chem. A, vol. 2, no. 14, pp. 4919-4926, Apr. 2014.

2. C. S. Lim and V. V. Atuchin, "Preparation and characterization of $\mathrm{Sr} 3$ V 2 O 8 nanoparticles performed via cyclic MAS route," Metamaterials VIII, vol. 8771, p. 877112, 2013.

3. R. Packiaraj, P. Devendran, S. Asath Bahadur, N. Nallamuthu, Structural and electrochemical studies of Scheelite type BiVO4 nanoparticles: synthesis by simple hydrothermal method, J. of Materials Science: Materials in Electronics vol. 29, pp.13265-13276, 2018.

4. L. Adijanto, V. Balaji Padmanabhan, R. Küngas, R. J. Gorte, and J. M Vohs, "Transition metal-doped rare earth vanadates: A regenerable catalytic material for SOFC anodes," J. Mater. Chem., vol. 22, no. 22, pp. 11396-11402, 2012.

5. A. Gorzsás, I. Andersson, and L. Pettersson, "On the fate of vanadate in human blood,” Eur. J. Inorg. Chem., no. 18, pp. 3559-3565, 2006.

6. B. Koo et al., "Hollow iron oxide nanoparticles for application in lithium ion batteries," Nano Lett., vol. 12, no. 5, pp. 2429-2435, 2012.

7. M. Casanova, L. Nodari, A. Sagar, K. Schermanz, and A. Trovarelli, "Preparation, Characterization and NH3-SCR activity of FeVO4 supported on TiO2-WO3-SiO2," Appl. Catal. B Environ., vol. 176-177, no. 1, pp. 699-708, 2015.

8. M. Casanova, A. Sagar, K. Schermanz, and A. Trovarelli, "Enhanced Stability of Fe2O3-Doped FeVO4/TiO2-WO3- SiO2SCR Catalysts,' Top. Catal., vol. 59, no. 10-12, pp. 996-1001, 2016.

9. M. Casanova, S. Colussi, and A. Trovarelli, "Investigation of Iron Vanadates for Simultaneous Carbon Soot Abatement and NH3- SCR,' Catalysts, vol. 8, no. 4, p. 130, 2018

10. Y. Luo et al., "Fe 2 VO 4 Hierarchical Porous Microparticles Prepared via a Facile Surface Solvation Treatment for High- Performance Lithium and Sodium Storage," Small, vol. 15, no. 7, pp. 1-10, 2019.

11. Y. V. Kaneti, Z. Zhang, J. Yue, X. Jiang, and A. Yu, "Porous FeVO4nanorods: Synthesis, characterization, and gas-sensing properties toward volatile organic compounds," J. Nanoparticle Res., vol. 15 , no. $9,2013$.

12. M. Hayashibara, "Lithiation characteristics of FeVO4," Solid State Ionics, vol. 98, no. 1-2, pp. 119-125, 1997.

13. N. Suresh Rao and O. G. Palanna, "Electrical and magnetic studies of iron (III) vanadate," Bull. Mater. Sci., vol. 18, no. 3, pp. 229-236, 1995.

14. S. Patoux and T. J. Richardson, "Lithium insertion chemistry of some iron vanadates," Electrochem. commun., vol. 9, no. 3, pp. 485-491, 2007.

15. H. Mandal et al., "Development of ternary iron vanadium oxide semiconductors for applications in photoelectrochemical water oxidation," RSC Adv., vol. 6, no. 6, pp. 4992-4999, 2016.

16. P. Sharma and T. S. Bhatti, "A review on electrochemical double-layer capacitors," Energy Convers. Manag., vol. 51, no. 12, pp. 2901-2912, 2010 .

17. J. Libich, J. Máca, J. Vondrák, O. Čech, and M. Sedlaříková, "Supercapacitors: Properties and applications," J. Energy Storage, vol. 17, no. March, pp. 224-227, 2018.

18. Y. Wang, Y. Song, and Y. Xia, "Electrochemical capacitors: Mechanism, materials, systems, characterization and applications,' Chem. Soc. Rev., vol. 45, no. 21, pp. 5925-5950, 2016 
19. S. M. Hosseinpour-Mashkani, A. Sobhani-Nasab, and M. Maddahfar, "Synthesis, Characterization and Investigation Magnetic and Photovoltaic Properties of FeVO4 Nanoparticles," J. Nanostructures, vol. 6, no. 1, pp. 70-73, 2016.

20. M. Ghiyasiyan-Arani, M. Salavati-Niasari, and S. Naseh, "Enhanced photodegradation of dye in waste water using iron vanadate nanocomposite; ultrasound-assisted preparation and characterization,' Ultrason. Sonochem., vol. 39, pp. 494-503, 2017.

21. M. Yeganeh Shad et al., "Wet-Chemical Synthesis and Electrochemical Properties of Ce-Doped FeVO4 for Use as New Anode Material in Li-ion Batteries," J. Inorg. Organomet. Polym. Mater., vol. 23, no. 6, pp. 1226-1232, 2013.

22. A. Š. Vuk, B. Orel, G. Dražič, F. Decker, and P. Colomban, "UVvisible and IR spectroelectrochemical studies of FeVO4 sol-gel films for electrochromic applications," J. Sol-Gel Sci. Technol.,vol. 23, no. 2, pp. 165-181, 2002.

23. B. Azambre, M. J. Hudson, and O. Heintz, "Topotactic redox reactions of copper(II) and iron(III) salts within VO $\chi$ nanotubes," J. Mater. Chem., vol. 13, no. 2, pp. 385-393, 2003.

24. P. Asen, S. Shahrokhian, and A. I. Zad, Iron vanadium oxysulfide nanostructures as novel electrode materials for supercapacitor applications, vol. 818, no. 2017. Elsevier B.V, 2018.

25. M. Balamurugan, G. Yun, K. S. Ahn, and S. H. Kang, "Revealing the Beneficial Effects of FeVO4 Nanoshell Layer on the BiVO4 Inverse Opal Core Layer for Photoelectrochemical Water Oxidation," J. Phys. Chem. C, vol. 121, no. 14, pp. 7625-7634, 2017.

\section{AUTHORS PROFILE}

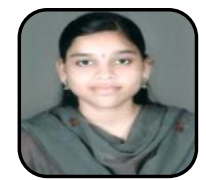

Ms. S. Ezhil Arasi born on 1994 in Erode, Tamilnadu. She obtained her Master degree in Physics in 2017 at Bharathiar University, Coimbatore. She joined $\mathrm{PhD}$ in 2017 under the supervision of Dr. A. Arivarasan at Kalasalingam Academy of Research and Education in Virudhunagar district. Her research interest is focused on the area of nanomaterials and carbon-based binary metal nanocomposites synthesis for energy storage device fabrication application.

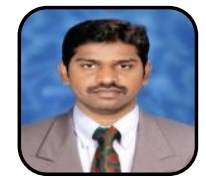

Dr. P. Devendran received his Ph.D degree in Physics from Madras University at Chennai in 2016, developing metal oxides and metal sulfide nano-catalysts for photocatalytic application. After he moved for postdoctoral studies at IRC, Kalasalingam academy of Research and education, he becomes an Assistant Professor of Physics at the same institution and presently began studying metal oxide modified graphene-based materials for energy storage device application and their surface science. He published more than $25+$ research articles and book chapters in reputed journals.

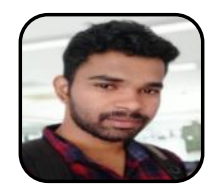

Mr. R. Ranjithkumar is a Ph.D Research scholar Department of Physics, Kalasalingam Academy of Research and Education, Krishnankoil, Tamilnadu, India. He got his M.Sc. degree from Bharathidasan University at Trichy in 2016, Tamilnadu, India. His current research focuses on the synthesis of Nanomaterials for Energy- storage device and Super capacitor Applications. He published one research article.

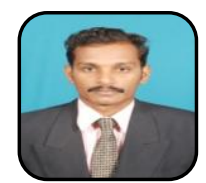

Dr. M. Krishnakumar received his $\mathrm{Ph} . \mathrm{D}$ degree in Physics from Madras University at Chennai in 2015 on Crystallography and Crystals Growth for optoelectronic and solar cell application. He joined as an Assistant Professor of Physics at Kalasalingam academy of Research and education, where he currently began studying Organic Perovskites for Energy Applications. He published more than $30+$ research articles and presented papers in international/ national conference, book chapters in reputed journals and proceedings.

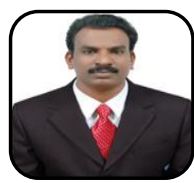

Dr. A. Arivarasan is currently working as Assistant Professor at Kalasalingam academy of Research and education, Virudhunagar, India. He completed his MSc (Physics) degree in Bharathidasan University, Trichy. He received both his M.Tech. (Nanotechnology) and Ph.D (Nanotechnology) degrees from Anna University in the years of 2010 and 2014, respectively on Quantum Dots for Solar Cell Applications. He has published nearly 20+ publications in peer reviewed international journals and more than 25 conference proceedings. His current research interests are in the fields of supercapacitor electrodes, redox electrolytes and device fabrications. 